\title{
The middle rectal artery detected by contrast-enhanced magnetic resonance imaging predicts lateral lymph node metastasis in lower rectal cancer
}

\author{
Yosuke Iwasa $^{1} \cdot$ Fumikazu Koyama $^{1,2}$ (D) $\cdot$ Nagaaki Marugami $^{3} \cdot$ Hiroyuki Kuge $^{1} \cdot$ Takayuki Nakamoto $^{1,2}$. \\ Shinsaku Obara ${ }^{1} \cdot$ Satoshi Nishiwada ${ }^{1} \cdot$ Takeshi Takei $^{1} \cdot$ Tomomi Sadamitsu $^{1} \cdot$ Satoshi Yamauchi ${ }^{3}$. \\ Kimihiko Kichikawa ${ }^{3} \cdot$ Masayuki Sho $^{1}$
}

Accepted: 9 February 2021 / Published online: 22 February 2021

(C) The Author(s) 2021

\begin{abstract}
Purpose Lateral lymph node (LLN) metastasis is one of the leading causes of local recurrence in patients with lower rectal cancer. Unfortunately, no diagnostic biomarkers are currently available that can predict LLN metastasis preoperatively. Accordingly, we investigated the relationship between the middle rectal artery (MRA) identified by contrast-enhanced magnetic resonance imaging (ceMRI) and LLN metastases.

Methods Data from 102 patients with lower rectal cancer who underwent surgery, and were evaluated by preoperative ceMRI, between 2008 and 2016 were reviewed retrospectively. Two expert radiologists evaluated the MRA findings. The diagnostic performance of MRA for LLN metastasis was evaluated by a multivariate analysis with conventional clinicopathological factors. Results The MRA was detected in 67 patients (65.7\%), including 32 (31.4\%) with bilateral MRA and $35(34.3 \%)$ with unilateral MRA. The tumor size, presence of the MRA, and clinical LLN status were significantly correlated with LLN metastasis. A multivariate analysis demonstrated that the presence of MRA $(P=0.045)$ and clinical LLN status $(P=0.001)$ were independent predictive factors for LLN metastasis. Furthermore, the sensitivity and negative predictive value of MRA for LLN metastasis were $95 \%$ and $97.1 \%$, respectively.

Conclusion We successfully demonstrated that MRAs could be clearly detected by ceMRI, and the presence of MRA robustly predicted LLN metastasis in patients with lower rectal cancer, highlighting its clinical significance in the selection of more appropriate treatment strategies.

Trial registration Trial registration number: retrospectively registered 2126

Trial registration date of registration: August 23, 2019
\end{abstract}

Keywords Rectal cancer $\cdot$ Lateral lymph node metastasis $\cdot$ Magnetic resonance imaging $\cdot$ Middle rectal artery

\section{Introduction}

Local recurrence of rectal cancer remains an important clinical problem associated with poor survival, severe morbidity, and

Fumikazu Koyama

fkoyama@naramed-u.ac.jp

1 Department of Surgery, Nara Medical University, 840 Shijo-cho, Kashihara 634-8522, Nara, Japan

2 Division of Endoscopy, Nara Medical University Hospital, 840 Shijo-cho, Kashihara 634-8522, Nara, Japan

3 Department of Radiology, Nara Medical University, 840 Shijo-cho, Kashihara 634-8522, Nara, Japan low likelihood if salvage. Lateral lymph node (LLN) metastasis, which occurs in approximately $15 \%$ of patients, is a leading cause of local recurrence in patients with lower rectal cancer [1]. In recent years, total mesorectum excision with a clear circumferential resection margin has become an established procedure for reducing local recurrence worldwide; however, the standard treatment strategies for the LLN area, such as chemoradiotherapy and LLN dissection, differ between western countries and eastern Asian countries in cases of lower rectal cancer [2-8]. Both neoadjuvant chemoradiotherapy and LLN dissection can reduce local recurrence after surgery; however, even chemoradiotherapy induces increased complications not only perioperatively but also postoperatively, including urinary, sexual, and bowel dysfunction [9-13]. This highlights the importance of pre-treatment diagnostic tools for risk stratification of LLN metastasis, which can facilitate 
decision-making for reducing unnecessarily excessive treatment for LLNs in patients with lower rectal cancer.

However, the pre-treatment diagnosis of the presence of LLN metastasis remains clinically challenging. Currently, the identification of enlarged LLNs evaluated on computed tomography (CT) and/or magnetic resonance imaging (MRI) is reportedly a risk factor for LLN metastasis [14-16]; however, the clinical LLN status as diagnosed by preoperative radiological modalities has not been established.

LLN metastasis has been considered associated with lateral lymphatic drainage along the middle rectal artery (MRA) [17, 18]. Traditionally, the MRA has been described as an artery that penetrates the pelvic plexus from the lateral side along the lateral ligament. However, cadaveric anatomical studies have shown the existence of other types of MRAs and a wide range of MRA detection rates, ranging from 12 to 97\% [19-25].

Recently, advances in diagnostic imaging have enabled the visualization of the detailed vascular anatomy. Bilhim indicated that the prevalence and anatomical findings of the MRA could be detected by CT angiography/digital subtraction angiography for male patients with lower urinary tract symptoms [21]. However, it is not practical to routinely perform CT angiography, as repeated exposure to radiation is required in order to capture the MRA clearly, which is thin and small.

In the present exploratory study, for the first time, we investigated the frequency of the MRA detected by contrastenhanced MRI (ceMRI) and successfully confirmed the utility of MRI-detectable MRAs for the identification of LLN metastasis, thus highlighting the clinical significance of this biomarker for the management of patients with lower rectal cancer.

\section{Patients and methods}

\section{Patients}

We retrospectively examined a total of 256 rectal cancer patients who underwent rectal resection at the Nara Medical
University Hospital between January 2008 and December 2016. Lower rectal cancer was defined as a tumor with a lower end located below the middle Houston's valve. Ninety-two patients with upper rectal cancer were excluded from this study. The exclusion criteria included absence of ceMRI ( $n$ $=50$ ), insufficient contrast imaging conditions $(n=8)$, and poor images caused by body movements $(n=4)$. Ultimately, 102 patients were included in this study (Fig. 1). All lower rectal cancer patients underwent preoperative examinations including computed tomography (CT), pelvic MRI, barium enema, and colonoscopy. Bilateral LLN dissection was performed for patients diagnosed with $\mathrm{cT} 3 / \mathrm{T} 4$ or suspected of having lymph node metastasis in the mesorectum and/or lateral pelvic area. Preservation of the autonomic nerves of the pelvic plexus was performed when LLN metastasis was not suspected. Surgically resected specimens were fixed in $10 \%$ phosphate-buffered formalin and embedded in paraffin. Tumors were classified according to the TNM staging system of the International Union Against Cancer (UICC) 8th edition. Two authorized pathologists evaluated the pathological findings.

Postoperative follow-up was performed for 5 years. Tumor markers were examined every 3 months, and all patients were evaluated using chest/abdominal contrast enhanced CT or pelvic MRI every 6 months after surgery according to the Japanese Society for Cancer of the Colon and Rectum (JSCCR) guidelines [26]. The presence of LLN metastasis was defined in the following cases: the patients who were diagnosed by a postoperative pathological examination or had LLN recurrence evaluated by imaging tests after surgery. When a new lesion was found on postoperative imaging and showed a gradual increasing trend, the lesion was diagnosed as a recurrent lesion.

This study was approved by the ethics committee of the Nara Medical University (No. 2126). All patients gave their informed consent for the use of their anonymized data via an opt-out method. Patients' consent to participate was obtained through an opt-out method.
Fig. 1 Flow diagram of this study cohort. ceMRI, contrast-enhanced magnetic resonance imaging

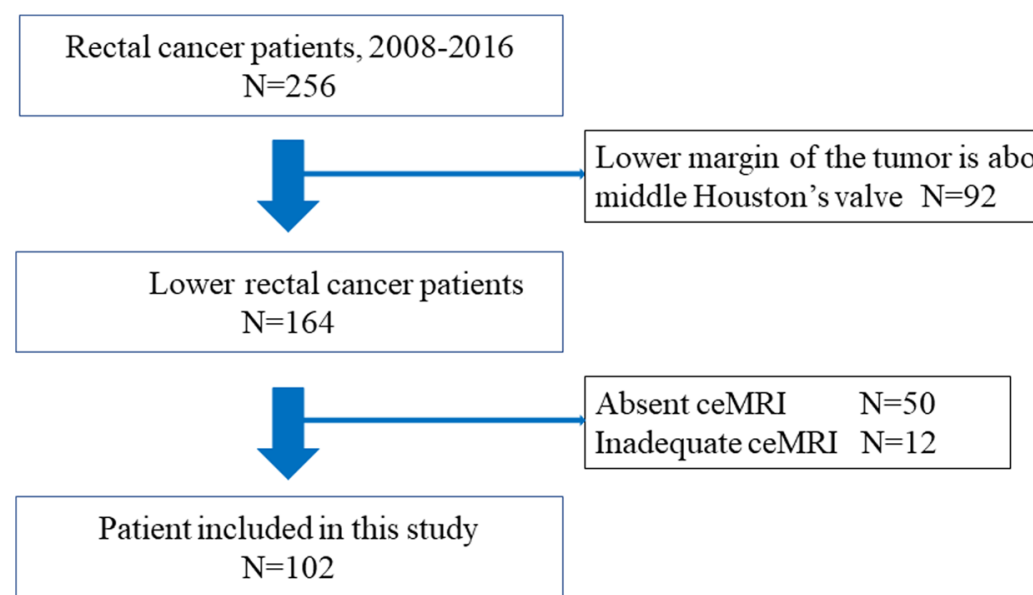




\section{Contrast-enhanced magnetic resonance imaging}

We have routinely used a 1.5-T MRI scanner (MAGNETOM Avanto; SIEMENS Healthineers, Erlangen, Germany) or 3-T MRI scanner (MAGNETOM Verio, Skyra; SIEMENS Healthineers, Erlangen, Germany) for the diagnosis of the depth of the primary rectal tumor and LLN swelling. Patients underwent MRI examinations in the supine position without preparation. T1-weighted gradient-echo sequencing was performed for enhanced MRI. For contrast-enhanced MRI, Gd-DTPA, Gd-DOTA, or Gd-BT-DO3A (0.1 $\mathrm{mmol} / \mathrm{kg}$ ) was infused into the vein. The slice thickness of all sequences was $1 \mathrm{~mm}$ and with a mean total time of $30 \mathrm{~min}$.

\section{Definition and evaluation of MRA}

Kiyomatsu et al. reviewed and classified MRAs into the following three branches: (i) antero-lateral (AL) type, which branches from the prostatic artery, inferior vesical artery, or uterine artery; (ii) lateral (L) type, which runs into the mesorectum via the lateral ligament; and (iii) posterolateral (PL) type, which runs into the rectosacral fascia consisted of posterior rectal wall (Fig. 2) [27]. In the present study, the MRA was defined as present when each artery was observed as running into the rectum from the outside of the mesorectum on axial slices of ceMRI. The presence of MRA was evaluated by two expert radiologists blinded to the clinicopathological data.

\section{Definition of the clinical LLN status and adaptation of LLN dissection}

In this study, we defined as cases as having a positive clinical LLN status when the LLN short axis exceeded $7 \mathrm{~mm}$ on preoperative pelvic MRI, with reference to previously reports $[14,15]$.
LLN dissection was adapted for lower rectal cancer patients with cT3/T4, suspected of having proximal lymph node metastasis, as well as positive clinical LLN status. We performed neoadjuvant chemotherapy (NAC) for such patients starting in 2014, and 21 patients received NAC in this study. Twenty-one patients received NAC, among whom 20 underwent LLN dissection.

\section{Statistical analyses}

Statistical analyses were performed using the SPSS software program, version 25.0 (IBM, Armonk, NY, USA). Categorical variables were expressed as numbers and percentages. In order to evaluate the relationship between the presence of the MRA and LLN metastasis, the sensitivity, specificity, positive predictive value, and negative predictive value were calculated. Fisher's exact test and the chi-squared test were used as appropriate to analyze the significantly different clinical factors between LLN metastasis-positive and metastasis-negative patients. Statistical analyses of all variables were considered significant at $P<0.05$. Multivariate logistic regression analysis was employed to evaluate clinicopathological variables and the presence of MRA that were significant on a univariate analysis for the detection of LLN metastasis.

\section{Results}

\section{Patients' characteristics}

Patients' clinicopathological characteristics are shown in Table 1. The 102 total patients with a median age of 64 (range $30-82$ ) years old included 64 men and 38 women. The median postoperative follow-up period was 49.1 months. A total of 16 (15.7\%) patients were diagnosed as LLN metastasis by pathological examination after surgery. Right and left LLN

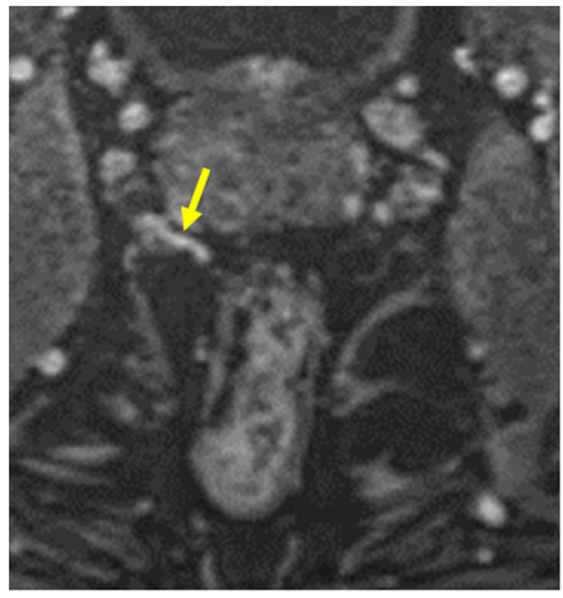

(i) AL type

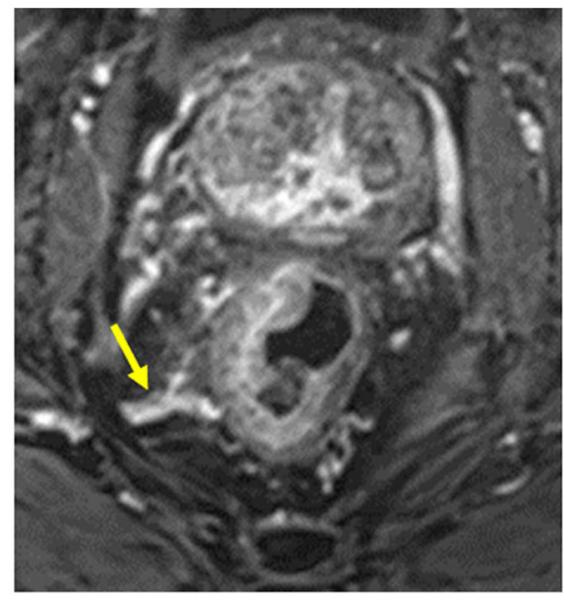

(ii ) L type

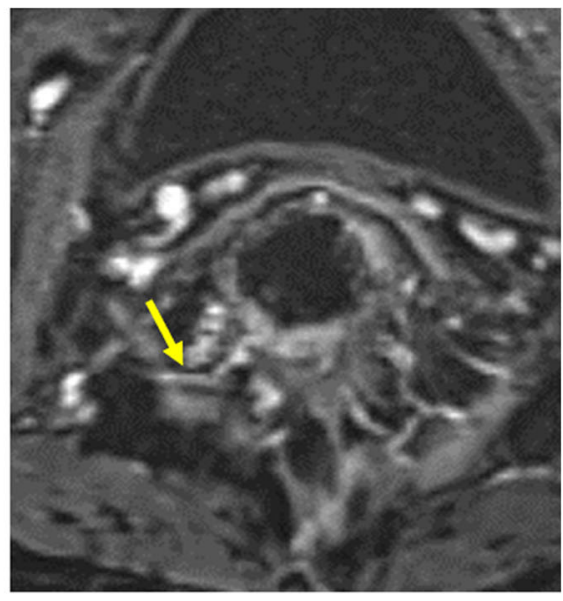

(iii) PL type

Fig. 2 Three types of middle rectal artery detected by contrast-enhanced MRI axial slices. (i) AL type, antero-lateral type; (ii) L type, lateral type; (iii) PL type, postero-lateral type 
Table 1 Clinicopathological characteristics of clinical cohort
No. of patients

$N=102$

Median age, years (range)

$64(30-82)$

Sex (male/female), $n(\%)$

$64(62.7) / 38(37.2)$

Tumor location $(\mathrm{Ra} / \mathrm{Rb} / \mathrm{P}), n(\%)$

$18(17.6) / 82(80.4) / 2(2.0)$

Distance from anal verge, $\mathrm{cm}$ (range)

$4.0(0-12.0)$

CEA level, $\mathrm{ng} / \mathrm{mL}$ (range)

$3.95(0.8-82.3)$

CA19-9 level, U/mL (range)

$11.5(1-1823)$

Lateral lymph node dissection, $n(\%)$

69 (67.6)

Median tumor size, mm (range)

$44(5-130)$

cT status, $n(\%)$

$\mathrm{cT} 1 \mathrm{~b} / \mathrm{cT} 2 / \mathrm{cT} 3 / \mathrm{cT} 4$

$7(6.9) / 17(16.7) / 54(52.9) / 24(23.5)$

$\mathrm{cN}$ status (proximal lymph node area), $n(\%)$

$\mathrm{cN} 0 / \mathrm{cN} 1 / \mathrm{cN} 2$

$30(29.4) / 52(51.0) / 20(19.6)$

Clinical lateral lymph node status, $n(\%)$

cLLN positive/cLLN negative

$26(25.5) / 76(74.5)$

Distant metastasis, $n(\%)$

cM0/cM1

$91(89.2) / 11(10.8)$

Neoadjuvant chemotherapy, $n(\%)$

Yes/no

$21(20.6) / 81(79.4)$

Median postoperative period, months (range)

$49.1(3.8-121.9)$

(y)pT status, $n(\%)$

(y)pT0/(y)pT1b/(y)pT2/(y)pT3/(y)pT4

$1(1.0) / 7(6.9) / 24(23.5) / 56(54.9) / 14(13.7)$

Proximal lymph node metastasis, $n(\%)$

(y)pN0/(y)pN1/(y)pN2

Lateral lymph node metastasis, $n(\%)$

Right side/left side

Lymphatic invasion, $n(\%)$

Positive/negative

Venous invasion, $n(\%)$

Positive/negative

Histopathological grade, $n(\%)$

G1/G2/G3

$43(42.2) / 29(28.4) / 30(29.4)$

$16(15.7)$

$13(12.7) / 7(6.9)$

$84(82.4) / 18(17.6)$

$78(76.5) / 24(23.5)$

$32(31.4) / 55(53.9) / 15(14.7)$

Tumor resection margin, $n(\%)$

$\mathrm{R} 0 / \mathrm{R} 1$

$93(91.2) / 9(8.8)$

Lateral lymph node recurrence, $n(\%)$

Present/absent

$4(3.9) / 98(96.1)$

LLN lateral lymph node, CEA carcinoembryonic antigen, CA19-9 carbohydrate antigen 19-9 metastasis was observed in 13 and 7 patients, respectively. LLN recurrences after surgery were occurred in 4 (3.9\%) patients. Taken together, LLN metastasis was confirmed in a total of $20(19.6 \%)$ patients in this study.

\section{The detection rate of MRA by ceMRI}

Using the ceMRI examinations, MRAs were detected in 67 (65.7\%) patients, and the numbers of AL/L/PL MRAs on the right side were $28(27.5 \%) / 35(34.3 \%) / 22(21.6 \%)$, while that on the left side were $16(15.7 \%) / 25(24.5 \%) / 18(17.6 \%)$, respectively. There were $32(31.4 \%)$ patients with bilateral MRAs and 35 (34.3\%) with unilateral MRAs. Thirty-five (34.3\%) patients had no detectable MRAs (Table 2). The number of identified MRAs was 1 vessel in 24 cases, 2 in 21,3 in 12,4 in 7, 5 in 2, and 6 in 1, respectively.

\section{The correlation between LLN metastasis and the frequency and trajectory of MRA}

The incidence of LLN metastasis in the patients with MRA was higher than in those without MRA $(P=0.002$, Table 3$)$. 
Table 2 MRA detection rate using contrast-enhanced MRI

MRA detection rate $(\%)$

$N=102$

\begin{tabular}{lc}
\hline Right side, $n(\%)$ & $28(27.5)$ \\
Antero-lateral type & $35(34.3)$ \\
Lateral type & $22(21.6)$ \\
Postero-lateral type & \\
Left side, $n(\%)$ & $16(15.7)$ \\
Antero-lateral type & $25(24.5)$ \\
Lateral type & $18(17.6)$ \\
Postero-lateral type & $32(31.4)$ \\
The number of patients who have detectable MRA, $n(\%)$ \\
Bilateral & $35(34.3)$ \\
Unilateral & $35(34.3)$ \\
Absent & $99(48.5 \%)$ \\
The number of pelvic-halves of MRA, & $(\%)$ \\
Present & $105(51.5 \%)$ \\
Absent &
\end{tabular}

$M R A$ middle rectal artery, MRI magnetic resonance image

Furthermore, LLN metastasis was significantly more frequent in the patients with bilateral MRAs (43.8\%) than in those without any MRAs $(2.9 \%)(P<0.001)$. Importantly, regardless of the tumor side in rectum, LLN metastasis frequently developed on the same side with MRAs $(21 / 99,21.2 \%)$. On the other hand, there were few instances of LLN metastasis on the without side $(3 / 105,2.9 \%)$.

\section{Multivariate analysis of predictive factors associated with LLN metastasis}

The correlation between the clinical factors and LLN metastasis is shown in Table 3. The tumor size, presence of MRA, and clinical LLN status were significantly correlated with LLN metastasis. A multivariate analysis revealed that the presence of MRA $(P=0.045)$ and clinical lateral lymph node status $(P=0.001)$ emerged as significantly independent predictive factors for LLN metastasis.

\section{The diagnostic accuracy of the MRAs detected by ceMRI examination for predicting LLN metastasis}

In this study, the diagnostic performance of the presence of MRAs detected by ceMRI is an important predictive factor for LLN metastasis. The sensitivity, specificity, accuracy, positive predictive value, and negative predictive value of the presence of MRAs detected by MRI for LLN metastasis were 95\% (19/20), 41.5\% (34/82), 61.8\% (63/102), 28.4\% (19/67), and $97.1 \%(34 / 35)$, respectively (Table 4$)$.

\section{Discussion}

In order to advance cancer treatment into a new era of precision medicine, the development of individualized treatment strategies for cancer patients is essential. In this exploratory study, we investigated for the first time the presence of MRAs using ceMRI and identified a significant correlation between MRAs and LLN metastasis. MRAs have been investigated anatomically using cadavers in several previous studies; however, clinical and radiological studies have not been conducted. The cadaveric studies mainly discussed the frequency, origin, and/or trajectory of MRAs. These anatomical studies have shown a wide range of detection rates because of variation in the definition of MRA. Kiyomatsu et al. reviewed the frequency and trajectory of MRA in detail and described three types of MRAs [27]. We therefore adapted this classification for the definition of MRAs in the present study because it covers almost all reported running patterns of MRAs.

For the preoperative evaluation of lower rectal cancer, high-resolution T2-weighted turbo spin-echo images are generally used for assessing the depth of tumor invasion, circumferential resection margin, and lymph node metastasis [28, 29]. In addition, gadolinium-enhanced and multiparametric MRI is used for staging the $\mathrm{T}$ status and evaluation of the efficacy of preoperative treatment $[30,31]$. Since T1weighted gradient-echo sequences can counteract the effects of adipose tissue and calcification in the mesorectum, ceMRI reveals a satisfactory performance for the identification of MRAs. Since MRAs were clearly visualized in the arterial phase of ceMRI, we used their presence as an indicator of lymphatic flow to the LLN region. While veins can be visualized with ceMRI, they are more difficult to evaluate than arteries because they are complex and ambiguous. Therefore, we thought that it was simpler and more practical to use MRA identified by ceMRI as a potent predictor of LLN metastasis.

In the present study, the prevalence of LLN metastasis was $19.6 \%$, which is consistent with previous reports $[2,32,33]$. From a clinical viewpoint, regarding LLN metastasis in lower rectal cancer, preoperative biomarkers for predicting LLN metastasis should have excellent negative predictive values, that is because it can facilitate to reduce unnecessary lymph node dissection and/or chemoradiotherapy. The MRA status demonstrated an adequate predictive performance for LLN metastasis in this study, with a sensitivity and negative predictive value of $95 \%$ and $97.1 \%$, respectively. Furthermore, in cases with no MRAs on one side, the rate of LLN metastasis on the same side was extremely limited to $2.9 \%$. These results highlight that MRA may help physicians and patients make decisions to avoid invasive treatments for LLN metastasis.

The gender, tumor location, proximal lymph node metastasis, tumor depth of invasion, lymphatic or venous invasion, histological tumor differentiation, and tumor size have been 
Table 3 Correlation between LLN metastasis and clinical and MRA status

\begin{tabular}{|c|c|c|c|c|c|c|}
\hline & \multicolumn{2}{|c|}{ LLN metastasis } & \multirow{2}{*}{$\begin{array}{l}\text { Univariate } \\
\text { analysis } \\
P \text { value }\end{array}$} & \multicolumn{3}{|c|}{ Multivariate analysis } \\
\hline & $\begin{array}{l}\text { Negative } \\
(n=82)\end{array}$ & $\begin{array}{l}\text { Positive } \\
(n=20)\end{array}$ & & $\begin{array}{l}\text { Odds } \\
\text { ratio }\end{array}$ & $95 \%$ C.I. & $\begin{array}{l}P \\
\text { value }\end{array}$ \\
\hline \multicolumn{7}{|l|}{ Clinical status } \\
\hline Age $(<64 \geq 64$ years $)$ & $39 / 43$ & $14 / 6$ & 0.072 & & & \\
\hline Sex (male/female) & $53 / 59$ & $11 / 9$ & 0.424 & & & \\
\hline $\begin{array}{l}\text { Tumor central location }(\mathrm{Ra} / \mathrm{Rb} \text {, } \\
\mathrm{P})\end{array}$ & $15 / 67$ & $3 / 17$ & 0.510 & & & \\
\hline $\begin{array}{l}\text { Distance from anal verge }(<5 / \geq 5 \\
\mathrm{cm})\end{array}$ & $40 / 42$ & $14 / 6$ & 0.088 & & & \\
\hline CEA level $(<5 / \geq 5 \mathrm{ng} / \mathrm{mL})$ & $52 / 30$ & $13 / 7$ & 0.895 & & & \\
\hline CA19-9 level $(<38 / \geq 38 \mathrm{U} / \mathrm{mL})$ & $75 / 7$ & $16 / 4$ & 0.141 & & & \\
\hline Tumor size $(<44 / \geq 44 \mathrm{~mm})$ & $37 / 45$ & $14 / 6$ & 0.046 & 1.328 & $0.389-4.537$ & 0.651 \\
\hline $\mathrm{cT}$ status $(\leq \mathrm{cT} 1, \mathrm{~T} 2 / \geq \mathrm{cT} 3, \mathrm{~T} 4)$ & $21 / 61$ & $3 / 17$ & 0.245 & & & \\
\hline $\begin{array}{l}\text { cN status (proximal lymph node } \\
\text { area) (positive/negative) }\end{array}$ & $56 / 26$ & $16 / 4$ & 0.303 & & & \\
\hline $\begin{array}{l}\text { Clinical LLN status } \\
\text { (positive/negative) }\end{array}$ & $13 / 69$ & $13 / 7$ & $<0.001$ & 7.409 & $2.316-23.697$ & 0.001 \\
\hline $\begin{array}{l}\text { Neoadjuvant chemotherapy } \\
\text { (yes/no) }\end{array}$ & $13 / 69$ & $8 / 12$ & 0.023 & & & \\
\hline Distant metastasis (cM0/cM1) & $74 / 8$ & $17 / 3$ & 0.369 & & & \\
\hline Tumor resection margin (R0/R1) & $75 / 7$ & $18 / 2$ & 0.561 & & & \\
\hline \multicolumn{7}{|l|}{ MRA status evaluated by ceMRI } \\
\hline MRA (positive/negative) & $48 / 34$ & $19 / 1$ & 0.002 & 8.922 & $1.045-76.159$ & 0.045 \\
\hline Laterality of MRA & & & $<0.001$ & & & \\
\hline Bilateral/unilateral/absent & $18 / 30 / 34$ & $14 / 5 / 1$ & & & & \\
\hline
\end{tabular}

$L L N$ lateral lymph node, $M R A$ middle rectal artery, $C E A$ carcinoembryonic antigen, $C A 19-9$ carbohydrate antigen 19-9, AL type antero-lateral type, L type lateral type, $P L$ type postero-lateral type reported as risk factors for LLN metastasis in previous reports $[2,3]$. Based on our multivariate analysis, the clinical LLN status and MRA identification on ceMRI were extracted as independent risk factors. In the present study, we defined LLN with a short axis of more than $7 \mathrm{~mm}$ as clinical LLN metastasis on preoperative pelvic MRI. The sensitivity and negative predictive value were $65.0 \%$ and $90.8 \%$, respectively. Fujita recently reported that the LLN diameter exceeding $5 \mathrm{~mm}$ was a risk factor for LLN metastasis [34]. However, the sensitivity and negative predictive value in that report were limited at $62 \%$ and $89 \%$, respectively. Fujita's findings and

Table 4 Diagnostic accuracy of MRA detected by contrasted-enhance MRI for LLN metastasis

\begin{tabular}{lllllll}
\hline & \multicolumn{3}{c}{ LLN metastasis } & & \multirow{2}{*}{ PPV (\%) } & NPV (\%) \\
\cline { 2 - 5 } & & Positive & Negative & Total & & \\
\hline \multirow{2}{*}{ MRA } & Positive & 19 & 48 & 67 & 28.4 & 97.1 \\
& Negative & 1 & 34 & 35 & & \\
\hline
\end{tabular}

$M R A$ middle rectal artery, $L L N$ lateral lymph node, $P P V$ positive predictive value, $N P V$ negative predictive value our own indicate that there are a certain number of patients who have LLN metastasis without LLN swelling. Micrometastasis without LLN swelling cannot be identified using the selection criteria based on the lymph node diameter. Coy et al. and Shimoyama reported that about $20 \%$ of patients with negative LLN metastasis had micro-metastasis detected using immunohistochemical staining $[35,36]$. Our results indicate that the assessment of the presence of MRAs by ceMRI precisely predicts LLN metastasis (including micro-metastasis) on each side in patients with lower rectal cancer.

Several limitations associated with the present study warrant mention. First, this study was a single-center, retrospective study. Second, we analyzed MRAs in a moderately sized clinical cohort. Third, no all MRAs are always going to be detected by ceMRI, although most of them may be visualized on 1-mm slice pelvic images. Finally, we need to prove the reproducibility of MRAs, since this is the first study. Further prospective studies are therefore needed in order to verify the detectability of MRAs by MRI via an anatomical approach and its validity as a significant predictor of LLN metastasis.

In conclusion, we successfully showed that MRAs could be clearly detected by ceMRI, and MRAs robustly predict LLN metastasis in patients with lower rectal cancer, 
highlighting their clinical significance in the selection of more appropriate treatment strategies. Furthermore, our study provides a framework for developing individualized treatment strategies for LLN and designing future clinical trials for patients with lower rectal cancer.

Code availability Not applicable.

Author contribution Study conception and design: FK and YI. Acquisition of data: YI, TT, and TS. Analysis and interpretation of data: SO, TN, and YI. Drafting of manuscript: YI and SN. Critical revision of manuscript: FK, YI, HK, and MS.

Data and materials availability Data sharing is not applicable in this study.

\section{Declarations}

Ethics approval This study was approved by our institutional ethics committee (No. 2126)

\section{Consent to participate Opt-out consent.}

\section{Consent for publication Opt-out consent.}

Conflict of interest The authors declare no competing interests.

Open Access This article is licensed under a Creative Commons Attribution 4.0 International License, which permits use, sharing, adaptation, distribution and reproduction in any medium or format, as long as you give appropriate credit to the original author(s) and the source, provide a link to the Creative Commons licence, and indicate if changes were made. The images or other third party material in this article are included in the article's Creative Commons licence, unless indicated otherwise in a credit line to the material. If material is not included in the article's Creative Commons licence and your intended use is not permitted by statutory regulation or exceeds the permitted use, you will need to obtain permission directly from the copyright holder. To view a copy of this licence, visit http://creativecommons.org/licenses/by/4.0/.

\section{References}

1. Chen JN, Liu Z, Wang ZJ, Mei SW, Shen HY, Li J, Pei W, Wang Z, Wang XS, Yu J, Liu Q (2020) Selective lateral lymph node dissection after neoadjuvant chemoradiotherapy in rectal cancer. World $\mathrm{J}$ Gastroenterol 26:2877-2888

2. Sugihara K, Kobayashi H, Kato T, Mori T, Mochizuki H, Kameoka S, Shirouzu K, Muto T (2006) Indication and benefit of pelvic sidewall dissection for rectal cancer. Dis Colon Rectum 49:16631672

3. Akiyoshi T, Watanabe T, Miyata S, Kotake K, Muto T, Sugihara K, Japanese Society for Cancer of the Colon and Rectum (2012) Results of a Japanese nationwide multi-institutional study on lateral pelvic lymph node metastasis in low rectal cancer: Is it regional or distant disease? Ann Surg 255:1129-1134

4. Fujita S, Mizusawa J, Kanemitsu Y, Ito M, Kinugasa Y, Komori K, Ohue M, Ota M, Akazai Y, Shiozawa M, Yamaguchi T, Bandou H, Katsumata K, Murata K, Akagi Y, Takiguchi N, Saida Y,
Nakamura K, Fukuda H, Akasu T, Moriya Y, Colorectal Cancer Study Group of Japan Clinical Oncology Group (2017) Mesorectal excision with or without lateral lymph node dissection for clinical stage II/III lower rectal cancer (JCOG0212). Ann Surg 266:201207

5. Cedermark B, Dahlberg M, Glimelius B, Pahlman L, Rutqvist LE, Wilking N, Swedish Rectal Cancer Trial (1997) Improved survival with preoperative radiotherapy in resectable rectal cancer. N Engl J Med 336:980-987

6. Kapiteijn E, Marijnen CA, Nagtegaal ID, Putter H, Steup WH, Wiggers $T$ et al (2001) Preoperative radiotherapy combined with total mesorectal excision for resectable rectal cancer. N Engl J Med 345:638-646

7. Sauer R, Becker H, Hohenberger W, Rodel C, Wittekind C, Fietkau $R$ et al (2004) Preoperative versus postoperative chemoradiotherapy for rectal cancer. N Engl J Med 351:1731-1740

8. Kim MJ, Kim TH, Kim DY, Kim SY, Baek JY, Chang HJ, Park SC, Park JW, Oh JH (2015) Can chemoradiation allow for omission of lateral pelvic node dissection for locally advanced rectal cancer? J Surg Oncol 111:459-464

9. Marijnen CA, van de Velde CJ, Putter H, van den Brink M, Maas $\mathrm{CP}$, Martijn $\mathrm{H}$ et al (2005) Impact of short-term preoperative radiotherapy on health-related quality of life and sexual functioning in primary rectal cancer: report of a multicenter randomized trial. J Clin Oncol 23:1847-1858

10. Peeters KC, van de Velde CJ, Leer JW, Martijn H, Junggeburt JM, Kranenbarg EK et al (2005) Late side effects of short-course preoperative radiotherapy combined with total mesorectal excision for rectal cancer: increased bowel dysfunction in irradiated patients-a Dutch colorectal cancer group study. J Clin Oncol 23:6199-6206

11. Swellengrebel HA, Marijnen CA, Verwaal VJ, Vincent A, Heuff G, Gerhards MF et al (2011) Toxicity and complications of preoperative chemoradiotherapy for locally advanced rectal cancer. Br J Surg 98:418-426

12. Fujita S, Akasu T, Mizusawa J, Saito N, Kinugasa Y, Kanemitsu Y, Ohue M, Fujii S, Shiozawa M, Yamaguchi T, Moriya Y, Colorectal Cancer Study Group of Japan Clinical Oncology Group (2012) Colorectal Cancer Study Group of Japan Clinical Oncology Group: Postoperative morbidity and mortality after mesorectal excision with and without lateral lymph node dissection for clinical stage II or stage III lower rectal cancer (JCOG 0212): results from a multicenter, randomized controlled, non-inferiority trial. Lancet Oncol 13:616-621

13. Saito S, Fujita S, Mizusawa J, Kanemitsu Y, Saito N, Kinugasa Y, Akazai Y, Ota M, Ohue M, Komori K, Shiozawa M, Yamaguchi T, Akasu T, Moriya Y, Colorectal Cancer Study Group of Japan Clinical Oncology Group (2016) Colorectal Cancer Study Group of Japan Clinical Oncology Group: Male sexual dysfunction after rectal cancer surgery: results of a randomized trial comparing mesorectal excision with and without lateral lymph node dissection for patients with lower rectal cancer: Japan Clinical Oncology Group Study JCOG0212. Eur J Surg Oncol 42:1851-1858

14. Yano H, Saito Y, Takeshita E, Miyake O, Ishizuka N (2007) Prediction of lateral pelvic node involvement in low rectal cancer by conventional computed tomography. Br J Surg 94:1014-1049

15. Arii K, Takifuji K, Yokoyama S, Matsuda K, Higashiguchi T, Yamaue $\mathrm{H}$ et al (2006) Preoperative evaluation of pelvic lateral lymph node of patients with lower rectal cancer: comparison study of MR imaging and CT in 53 patients. Langenbeck's Arch Surg 391:449-454

16. Ogura A, Konishi T, Cunningham C, Garcia-Aguilar J, Iversen H, Toda S, Lee IK, Lee HX, Uehara K, Lee P, Putter H, van de Velde CJH, Beets GL, Rutten HJT, Kusters M, on behalf of the Lateral Node Study Consortium (2019) Neoadjuvant (chemo)radiotherapy with total mesorectal excision only is not sufficient to prevent lateral local recurrence in enlarged nodes: results of the multicenter lateral 
node study of patients with low cT3/4 rectal cancer. J Clin Oncol 37:33-43

17. Blair JB, Holyoke EA, Best RR (1950) A note on the lymphatics of the middle and lower rectum and anus. Anat Rec 108:635-644

18. Miscusi G, Masoni L, Dell'Anna A, Montori A (1987) Normal lymphatic drainage of the rectum and the anal canal revealed by lymphoscintigraphy. Colo-proctology 6:171-174

19. Sato K, Sato T (1991) The vascular and neuronal composition of the lateral ligament of the rectum and the rectosacral fascia. Surg Radiol Anat 13:17-22

20. Didio LJ, Diaz-Franco C, Schemainda R, Bezerra AJ (1986) Morphology of the middle rectal arteries. A study of 30 cadaveric dissections. Surg Radiol Anat 8:229-236

21. Bilhim T, Pereira JA, Tinto HR, Fernandes L, Duarte M, O'Neill JE, Pisco JM (2013) Middle rectal artery: myth or reality? Retrospective study with CT angiography and digital subtraction angiography. Surg Radiol Anat 35:517-522

22. Jones OM, Smeulders N, Wiseman O, Miller R (1999) Lateral ligaments of the rectum: an anatomical study. Br J Surg 86:487489

23. Nano M, Dal Corso HM, Lanfranco G, Ferronato M, Hornung JP (2000) Contribution to the surgical anatomy of the ligaments of the rectum. Dis Colon Rectum 43:1592-1598

24. Boxall TA, Smart PJ, Griffiths JD (1963) The blood-supply of the distal segment of the rectum in anterior resection. Br J Surg 50:399404

25. Ayoub SF (1978) Arterial supply to the human rectum. Acta Anat 100:317-327

26. Hashiguchi Y, Muro K, Saito Y, Ito Y, Ajioka Y, Sugihara K (2020) Japanese Society for Cancer of the Colon and Rectum (JSCCR) guidelines 2019 for the treatment of colorectal cancer. Int J Clin Oncol 25:1-42

27. Kiyomatsu T, Ishihara S, Murono K, Otani K, Yasuda K, Nishikawa T, Tanaka T, Hata K, Kawai K, Nozawa H, Yamaguchi H, Watanabe T (2017) Anatomy of the middle rectal artery: a review of the historical literature. Surg Today 47:14-19

28. Nougaret S, Reinhold C, Mikhael HW, Rouanet P, Bibeau F, Brown G (2013) The use of MR imaging in treatment planning for patients with rectal carcinoma: have you checked the "DISTANCE"? Radiology 268:330-344

29. Al-Sukhni E, Milot L, Fruitman M, Beyene J, Victor JC, Schmocker S et al (2012) Diagnostic accuracy of MRI for assessment of $\mathrm{T}$ category, lymph node metastases, and circumferential resection margin involvement in patients with rectal cancer: a systematic review and meta-analysis. Ann Surg Oncol 19:2212-2223

30. Hötker AM, Garcia-Aguilar J, Gollub MJ (2014) Multiparametric MRI of rectal cancer in the assessment of response to therapy: a systematic review. Dis Colon Rectum 57:790-799

31. Tamakawa M, Kawaai Y, Shirase R, Satoh T, Akiba H, Hyodoh H, Hareyama M, Furuhata T, Hirata K, Hasegawa T (2010) Gadolinium-enhanced dynamic magnetic resonance imaging with endorectal coil for local staging of rectal cancer. Jpn J Radiol 28: 290-298

32. Fujita S, Yamamoto S, Akasu T, Moriya Y (2003) Lateral pelvic lymph node dissection for advanced lower rectal cancer. Br J Surg 90:1580-1585

33. Ueno M, Oya M, Azekura K, Yamaguchi T, Muto T (2005) Incidence and prognostic significance of lateral lymph node metastasis in patients with advanced low rectal cancer. Br J Surg 92:756763

34. Fujita S, Yamamoto S, Akasu T, Moriya Y (2009) Risk factors of lateral pelvic lymph node metastasis in advanced rectal cancer. Int $\mathrm{J}$ Color Dis 24:1085-1090

35. Coy CS, Meirelles LR, Leal RF, Ayrizono ML, Goes JR, Fagundes JJ (2010) Evaluation of lateral lymph node metastasis in advanced distal rectal cancer. Hepatogastroenterology 57:1363-1366

36. Shimoyama M, Yamazaki T, Suda T, Hatakeyama K (2003) Prognostic significance of lateral lymph node micrometastases in low rectal cancer: an immunohistochemical study with CAM5.2. Dis Colon Rectum 46:333-339

Publisher's note Springer Nature remains neutral with regard to jurisdictional claims in published maps and institutional affiliations. 